\title{
Social Networks and Politics: The Use of Facebook in the Costa Rican 2014 Presidential Election
}

\author{
Roberto Cruz Romero \\ University of Costa Rica
}

\begin{abstract}
New Information and Communication Technologies (ICTS) have changed the way how people interact in the new virtual spaces. Politics, as an expression of such interaction, is no exception to this. This study focuses on the contraposition of the mobilizing and normalizing theses, in its aim to demonstrate that social networks are a valid source for electoral political processes analyses. Therefore, the research focuses on the online dynamics generated by the five major presidential candidates in Costa Rica, during the 2013-2014 electoral campaign, in their official Facebook profiles. The study assess each candidate's communication, interaction and, finally, mobilization capabilities as from these virtual spaces. Such data are complemented and contrasted with national opinion polls results, as well as the final election results, finally showing Facebook's political value.
\end{abstract}

\section{Introduction}

This research is supported by a multidisciplinary approach coordinated from the Information and Knowledge Society Program (PROSIC -in Spanish) of the University of Costa Rica (UCR), which aims to show the value of the tools that Information and Communication Technologies (ICTs) hold in the various areas of social and scientific knowledge; in this specific case, political sciences. Specifically, it will address the case of the Costa Rican presidential election, and it how much (if any) did the parties involved took advantage of this tools and ICTs.

Following this, the project builds upon and develops its approach, albeit, from joint efforts from the computer science field. As to be explained in latter sections, the data corpus was designed, extracted and built in close collaboration with the School of Informatics and Computer Science of the UCR, bringing together specialists in both fields. Although these colaborators are not quoted directly as coauthors, they're given the proper acknowledgement. In such manner, the full version of this research can be found at PROSIC's 2014 annual report, available in digital format on the Program's website (http:// prosic.ucr.ac.cr/materiales/informes/informe-2014).

For the moment, there's no complete translation, but a shorter version of the study can be found in the proceedings of the London i-Society International Conference 2015[1].

In such way, this paper aims to summarize the most relevant empirical aspects of the aforementioned research, emphasizing the study's relevance as of the socio-political phenomena on the Internet, as it represents an almost-universal platform for action and interaction. The focus of this paper is intended to reinforce findings relating to political uses of ICTs, specifically Internet and social networking sites (SNS) such as Facebook, and its electoral and political repercussions. The selection of such site (Facebook) as a study case is based on the fact that it's the most used and widespread digital social platform in the country [2], accounting for nearly nine of out every ten SNS users.

Additionally, given the particularity of the subject analyzed, this study focuses on two strains of the political usage of Internet; a) the mobilization/normalization theories, and $\mathbf{b}$ ) the predictive capacities of online data. The latter being the most influential to the research's purposes. It is, however, valuable to observe both dimensions in contrast to what the extracted data used for the analyses show. In the first case, it is noticeable that parties have no clear identification of what normalizing, nor mobilizing could really mean for them. Also, not the parties neither news outlets and other agents perceived the theoretical and -finally- practical value of Internet as to have major incidence, and quite possibly predictive functions.

Therefore, the study is emphatically oriented towards a particular question: Does the Internet, SNS precisely, work predictably in relation to the political behavior displayed in the offline Costa Rican society? Or, on the contrary, are SNS a mere reflection of such offline behaviors? To try and answer this questions, this paper is structured in four main parts; the present 
introduction serves as a motivation for the reader, to get acquainted with the subject and familiarized with the study case. Then, a brief sub-section describes the data extraction process and the analyses methodology. Following this, another sub-section addresses the key conceptual and theoretical terms that best serve to analyze and comprehend this phenomenon. The second section focuses on the most relevant empirical data analyses, this will serve as basis for which to generate a discussion around key issues regarding the value and pertinence of ICTs and SNS. That is the third section. Finally, some last considerations on the subject are drawn upon the lines previously stated, adding some more insight into the tendencies and future of political Internet usage.

\section{Method}

As stated before, the efforts regarding the data extraction must be recognized to Professor Edgar Casasola Murillo, of the Research Center for Information and Communication Technologies (CITIC -in Spanish), of the School of Informatics and Computer Science at the University of Costa Rica. This methodology design was developed in a joint effort to assure both technical reliability as well as to mantain a link with the research goals. Also, the acknowledgement must be made also to Proffesor Casasola's team (Rubén Jiménez and Emmanuel Abarca), who programed Sentímetro, an application platform developed by CITIC to obtain access to Facebook's API and mine a database of approximately 400,000 posts, extracted directly from the official pages of the five major presidential candidates in Costa $\mathrm{Rica}^{1}$; all relating to the electoral process. That is to say, the data corpus consisted of posts made by the candidates themselves, comments to such posts made by people or by directly posting on the candidates' profiles, and even replies to these comments. The time span in this study was limited to the duration of the electoral campaign (i.e. October 2013 - April 2014).

\subsection{Concepts}

Primarily, this research is based on two major elements within a broad conceptual framework that shapes the research on the Internet and its sociopolitical usage; namely, characterization of SNS use in relation to the end users. That is, that which, in the context of new trends in information and communication, creates certain social reactions, through each person participating in such contexts of hyper-reality. Elements such as selfefficacy [3] and political engaement [10] are central to recent studies on Internet and politics, especially SNS. This paper does not drift much apart from it.
Plus, this paper focuses on the typology given by Wells [ ], in which Internet usage is defined from two paradigms; this epistemological frameworks correspond to the difference in which information is consumed and interacted with. Such characterization refers to the two main audiences of online content: the younger and actualizing crowds and the older and dutiful portions. In line with what is argued here, the first group acts more intensively and dynamically creates and moves information. The latter mantains more structured and hierarchical schemes of information consumption. And, as mentioned before, this refers directly to the normalizing-movilizing dichotomy.

Regarding this, self-efficacy implies the condition by which individuals break traditional structures of information consumption and processing; with the existence of new and diverse sources of information, as well as new and traditional media outlets, people seek to approach information by their own means. Another way to look at it is to understand it as the feeling of relative sufficiency each person experiences, regarding their interests and needs in terms of news usage [3].

Recent studies [6] [7] [8] [9] [17] abide by the notion that these attitudes promote a critical posture in people regarding political rallying and campaigning, phenomena used to be seen as impersonal and detached from themselves. Thus, highlighting the role of Internet, as a magnifier of social reality, one could argue that virtual expressions on SNS are cause and effect of social disruptions in the real world. Volatilization and polarization [4] are two of the most notorious consequences that intensive political Internet usage tends to generate, as more traditional schemes break down in favor of more multidimensional, multipolar ecosystems. Such is the environment in which one must discern whether SNS offer normalizing -real-world, reflective traits- or movilizing -habermasian, pluralistic traits- options to the people, by the parties. And, whether or not are the parties, their structures and the whole party system threatened under this potential behaviors.

\section{Data Analysis}

As stated before, the data corpus used for the analysis was obtained from each of the presidential candidates' Facebook profiles; this means that it only considers any activity recorded within these profiles. Two particular reasons were considered for this methodology: a) it minimizes the difficulty in obtaining such data; and, conceptually more relevant from the theoretic standpoint here discussed, b) based on the assumption that people seek to interact with the candidate of their choice (or even one that they adverse), it represents a stronger civic engagement and a more critical consideration of 
TABLE 1. Distribution of Comments and Replies for each presidential Candidate. Costa Rica, 2013-2014.

\begin{tabular}{|l|l|r|r|r|r|}
\hline \multirow{2}{*}{ Candidate } & \multicolumn{3}{|l|}{ Posts } & \multicolumn{1}{l|}{} \\
\cline { 2 - 6 } & Facebook ID & \multicolumn{1}{l|}{ Comment } & \multicolumn{1}{l|}{ News } & \multicolumn{1}{l|}{ Replies } & \multicolumn{1}{l|}{ Total } \\
\hline Johnny Araya & JohnnyArayaMonge & 69,068 & 740 & 8,995 & 78,803 \\
\hline Rodolfo Piza & RodolfoPizaR & 11,824 & 1,276 & 430 & 13,530 \\
\hline Luis Guillermo Solís & luisguillermosolisr & 138,515 & 1,038 & 13,667 & 153,220 \\
\hline Otto Guevara & ottoguevaraguth & 39,086 & 1,097 & 7,857 & 48,040 \\
\hline José María Villalta & villaltaJM & 86,163 & 468 & 16,898 & 103,529 \\
\hline Total & & $\mathbf{3 4 4 , 6 5 6}$ & $\mathbf{4 , 6 1 9}$ & $\mathbf{4 7 , 8 4 7}$ & $\mathbf{3 9 7 , 1 2 2}$ \\
\hline
\end{tabular}

the electoral process from the users. Thus, there's a reinforcement of the idea that people who are actively engaged in social media during electoral processes, do so in a more direct way, pursuing interaction with the corresponding political characters of their linking. Table 1 shows the distribution of these data in an introductory and disaggregated way.

What the table shows, at first, is the identifier (ID) of each candidate's Facebook page; this ID registers the candidates' profile and any activity carried out by them. Then, three columns under the category of Posts are presented: News, Comment and Replies. Such nomenclature stands as follows: the News column refers to each entry made by each candidate, (i.e. every post made by them). Thus, Comment refers to each sub-entry generated from News entries, while the Replies column refers to each entry made in response to the ones posted as comments. In such logic, News generate Comments, and Comments generate Replies.

However, this information does not represent much; therefore, to contextualize the analysis proposed here, Figure 1 is presented as to show the intended

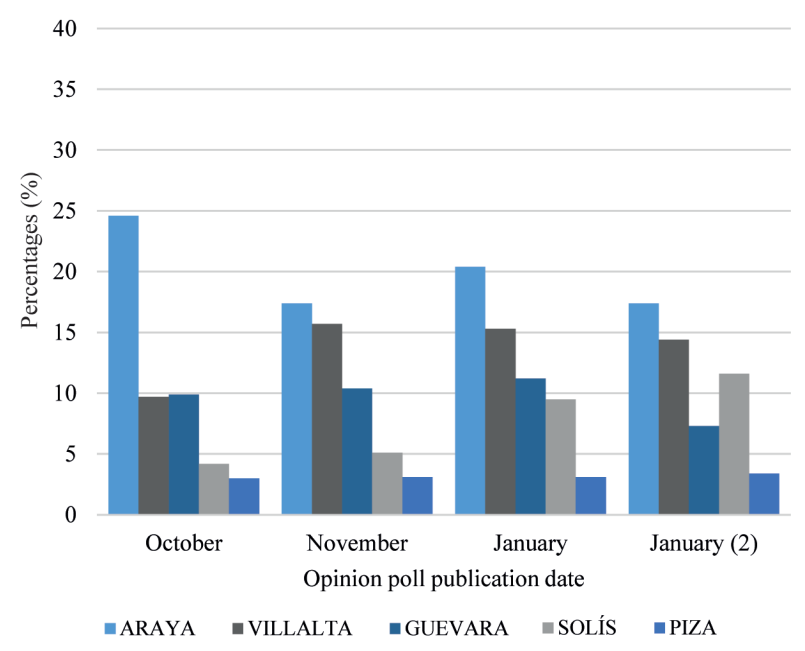

Figure 1. Voting intention for the presidential candidates, October 2013 - January 2014 voting behavior recorded in periodic national surveys carried out by the Centre of Research and Political Studies (CIEP) [5] of the University of Costa Rica, in collaboration with the University's nation-wide weekly newspaper. This will serve as a starting point for interesting comparisons with respect to the electorate's online and offline dynamics.

Now, to build upon an image that complements the prior, Figure 2 shows the total Facebook activity accounted for all comments in each profile, and how, if the trends shown in both graphs are taken as a basis, other notable aspects emerge. For example, as shown in the first opinion poll of the CIEP, Araya showed great popularity during October 2013, showing then a progressive decay. Whilst in the virtual dimension he showed an irregular behavior during the first three months, in terms of generating activity within his profile. January marks a peak of Facebook activity for him due to multiple causes occurred in the offline world (lack of financial liquidity from his party, communication strategies (mis) management, closeness to the final voting, etc.), but a precipitate decline is showed towards the second polling

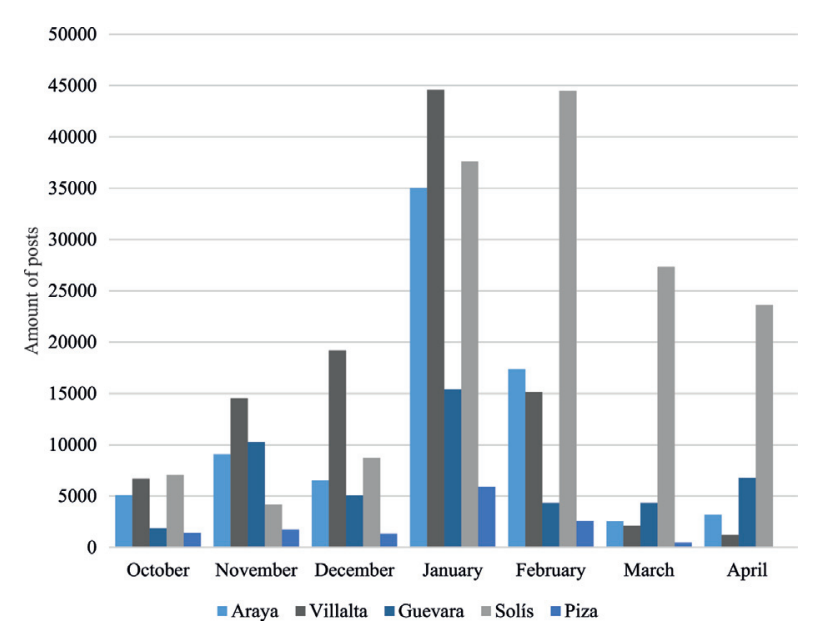

Figure 2. Comments in the candidate's profiles, October 2013 - April 2014 
round, which can be attributed to his "resignation" from campaigning in March, an unregistered event in Costa Ricasn political history. Keeping certain similarities with the observed online behavior, Villalta showed sustained growth until January, surpassing all Facebook activity any other candidates had in their profiles up to that point. Then, following the outcome of the first polling round, Villalta's Facebook activity practically ceased. Moreover, worthy of note, is the -certainly irregular- behavior generated in Solis' profile, accounting for three months of relative under-the-radar behavior as to profile activity. However, January marks a turning point for Solis, as his profile's activity rockets, nearly quadrupling the previous month's activity; then dominating this category in February, and basically running solo in March and April (see Figure 2).

Subsequently, if one pays close attention to what Table 1 shows, one can observe the amount of posts each candidate made, i.e. the so-called News. What this category displays is how consistent were the candidates along the duration of the campaign (4 months for the regular process plus two more months for the second polling round). These data show how Piza was the most active candidate, surpassing Villalta who, inversely, was the candidate whose profile received the most comments. In this sense, there's an inverse relationship between these two candidates; on the one hand, Piza posted about 350 times in his profile (between the months of November 2013 and January 2014) while, on the contrary, Villalta only did so 180 times up until January, where he showed his peak of activity.

Following these figures, Table 2 displays the difference between the overall activity of each candidate. This table compares the uneven nature of the way politicians engage with their followers. It shows just how contrasting the paradigmatic and programatic views of the contesting parties really are. It stands out as a true means of verification of the traditional vs nontraditional politics, and, possibly, the organic dynamics of Internet politics in relation to old-fashioned parties and antiquated party structures.

Thus, Table 2 shows each candidate's total activity, as it reflects inverse tendencies; Piza and Guevara were most active Facebook users out of the five, but Villalta and -mainly- Solís were the two candidates who obtained the most attention from general Facebook users, as each received over one hundred thousand posts on their profiles. Although, it needs to be reminded of such proportions, as the interactive trait doesn't really comply with these numbers. That is, as Villalta received over 220 comments for each of his posts, but he only replied to posts and comments a total of 60 times. On the contrary, Piza and Araya were the candidates who interacted the most; the latter having replied to his or other comments over two thousand five hundred times. It may be noted as well that each candidate's capacity to reply and interact is diminished as the amount of posts and comments they receive grows (see Solis' and Villalta's received/posted ratio).

So far, the characterization of the campaign seems to lead one into believing that not all candidates took the advantage they could out of this specific ICT platform. Political parties seem to have a trusted nexus with traditional politics, not really understanding how much they could gain of technological approaches in campaigning. Casuistically sapeaking, the example of Villalta's Facebook campaign may appear succesful; however, through interviews with his communication staff, it came to show that his party never had an e-campaign strategy, and relied heavily on organic growth which, compared with the opinion polls observed beforr, one could argue about the potential movilizing effect of his campaign. The opposite might be said about Piza or Araya, whose main efforts went onto taking advantage of the normalizing effect Internet, and Facebook specifically, displayed. Interview-based evidence suggest this also has to do with the political system's development and context. In this line, there are two main groups to be distinguished amongst the parties in terms of ICT adoption and usage (and the intention of such usage). These are: a) the ones relying on the affordances that Facebook offers, and b) the ones relying on traditional campaigns, translating (normalizing) their offline campaign into their online assets, and viceversa.

Now, turning the attention back to the way in which the campaign developed, Figures 3 and 4 show how the

TABLE 2. Comments posted and received by each candidate, October 2013 - April 2014

\begin{tabular}{|l|r|r|r|}
\hline Candidate & Posted & Comments & Comments per Post \\
\hline Johnny Araya & 740 & 78,065 & 105 \\
\hline Otto Guevara & 1,097 & 46,945 & 43 \\
\hline José M.Villata & 468 & 103,061 & 220 \\
\hline Luis G. Solís & 1,038 & 152,183 & 147 \\
\hline Rodolfo Piza & 1,276 & 12,254 & 10 \\
\hline Total & $\mathbf{4 , 6 1 9}$ & $\mathbf{3 9 2 , 5 0 8}$ & $\mathbf{8 5}$ \\
\hline
\end{tabular}




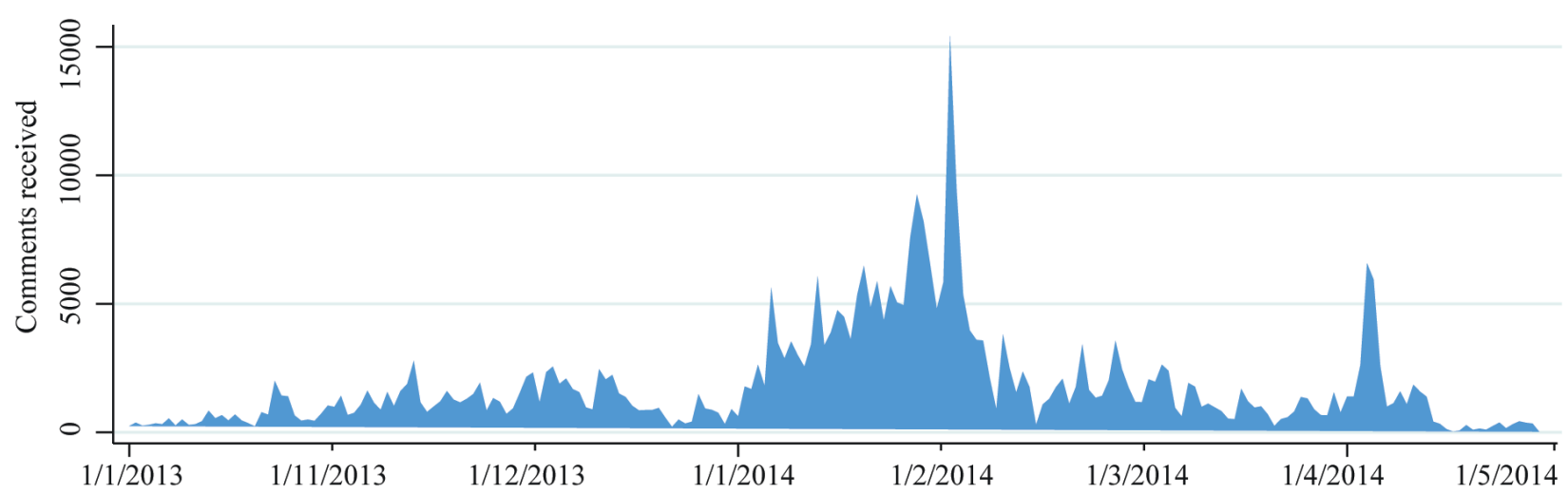

Figure 3. Timeline of the Costa Rican presidental campign, by Comments received by the candidates in their Facebook profile, October 2013 - April 2014

commenting behavior, aggregately and individually, occurred throughout the entire campaign for the candidates in their profiles. The former presents the way in which all comments for all five candidates were accounted, including the second election round. Besides showing the amount of posts that indicate the activity, it highlights the behavioral pattern that characterized the campaign; a discrete and low-profile first months, leading up to a very intense final month of activity. Although this indicates something out of the realm of what's being discussed here, it noticeable to relate this to what opinion polls also say about this phenomenon: there's very little interest on the issue the first months into campaign, and as the race intensifies, so does support.

Additionally, the latter displays a series of events that generated big reactions from active Facebook users. It breaks down such values according to the activity recorded in the profile of each candidate. What's shown in this figure confirms the widespread, aforementioned idea that dominated the campaign, which claimed that the citizenship -whether by discontent or lack of knowledge- remained distant from the electoral process, being January the moment it shows a relevant increase in the activity (see Figure 3 and Figure 4).

Thus, observing the events marked on Figure 4, one can see the close relation of such "real-world" milestones with the behaviors recorded in the Facebook profiles. In other words, there's a clear indication of a mobilizing pattern [6] [7] [8] [9]. This means that not only SNS, on the one hand, reflect some offline conducts, but they serve as a means of new behavioral outputs, setting trends for the offline world. In a descriptive way, one can notice that the most prominent peaks in the trend lines were caused by a number of non-related events. Firstly, communication and publicity issues, followed by TV debates and opinion polls and, lastly, the very same election day and post-election events. Again, there are a mixture of online phenomena and offline milestones that influenced the debate agenda and the course of the campaign.

This is particularly interesting because offline events generated debate and discussion online; and, on the other hand, online activity resonated on almost every news and content-producing agency, creating a clycle environment of political news consumption [3]. In such manner, sites like Facebook appear as a second screen [10] for most of everyday activities, being electoral processes a particularly intense context; but, also functioning as bricolage [11] generator, through the information cascades that have notable repercussions on public opinion and, by such, in the general perception of politics and its dynamics. The extended reach of online content into the offline world appears to have a deep impact on real-life opinions which, with the help of SNS as Facebook, translate into a dual and correalated reality where content is at the base of ideological and attitude constructs, that then reflect on adn offline. Hence, political information continues to cycle, with Facebook as its medium.

To this respect, candidates utilized Facebook as an informative resource, never really obtaining the full benefits of such Web 2.0 platform. This could have worked as a normalizing factor [12], notwithstanding the mobilizing trait that it mainly displayed. That is, as said before, candidates, and their parties, although sometimes taking advantage of the affordances and organic growth that Facebook endorses, never really engaged in truly interactive and dynamic relations with users.

Taking into consideration other characteristics of the metrics obtained, Figure 5 evidences the impact of the activity of each candidate. It shows another factor that must come into consideration when analyzing the role of SNS in electoral politics: the reaction generated by each publication made by each candidate. Not only does it serve as one indicator of fluctuating behavior and the intense electoral dynamics on the Internet, but 


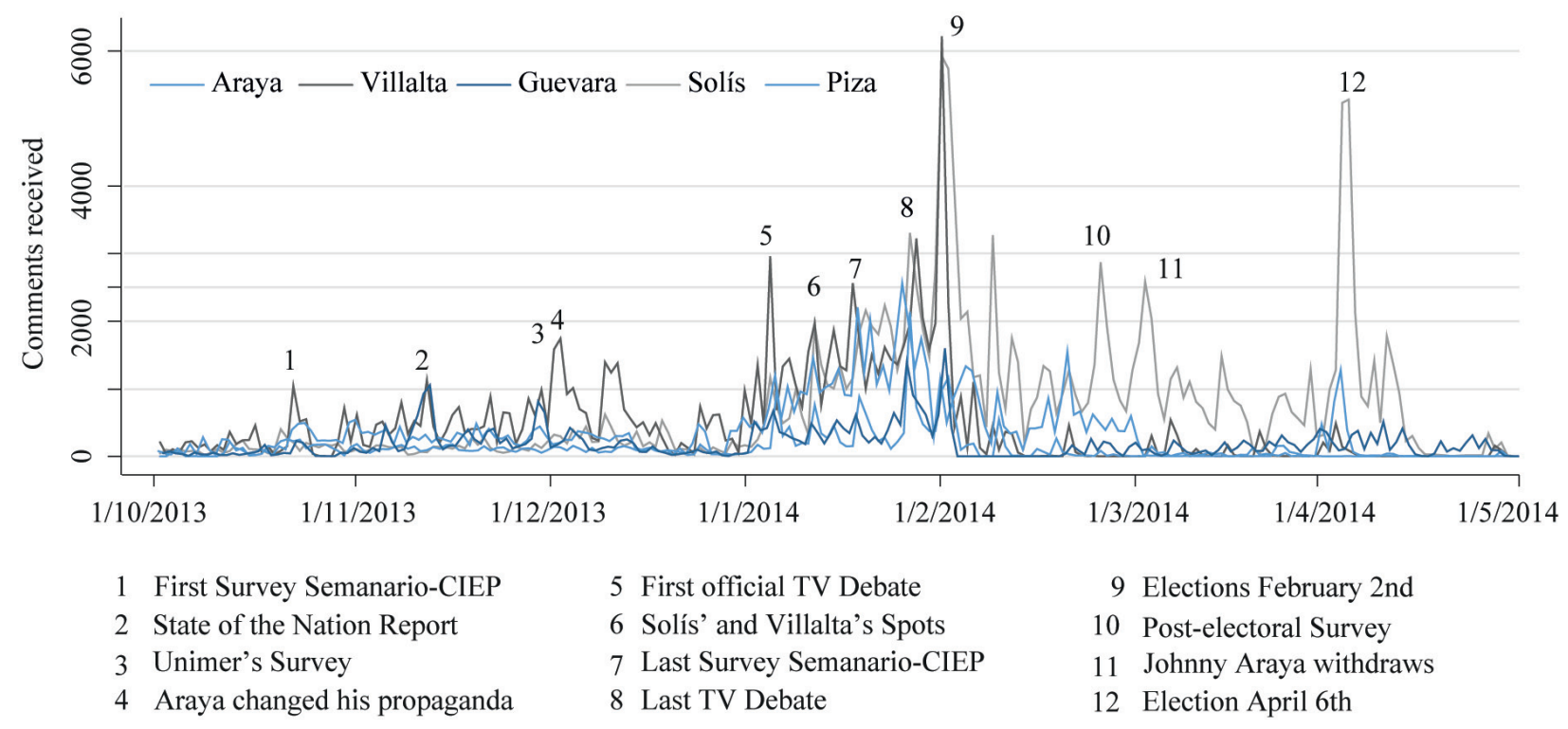

Figure 4. Timeline of the Costa Rican presidental campign, by Comments received by each candidate in their Facebook profile, October 2013 - April 2014

as a characterization of preferences, motivations and idiosyncratic traits of the people. This figure shows the number of comments generated from certain posts by each candidate, according to the temporal context of the campaign. Such figure shows a quite regular overall behavior, as well as a sustained growth up until February, then decreasing in the same way, in an almost identical manner as shown in the previous graphs. However, certain irregularities of unusually periodic activity peaks appear most notably.

Descriptively, Solis had the most commented post out of all five candidates during the campaign (from

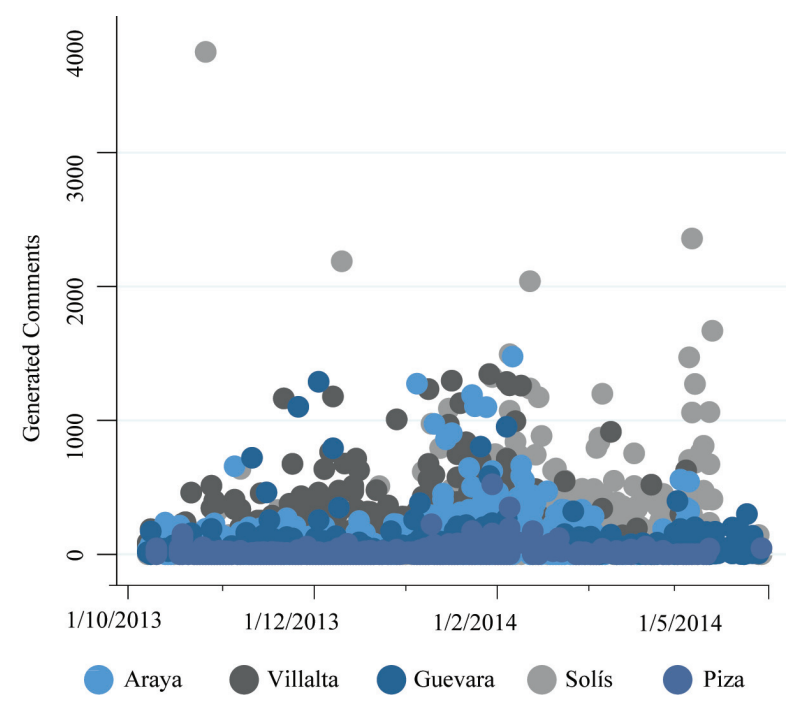

Figure 5. Most commented posts, by candidate, October 2013 - April 2014
October 2013 thru April 2014); his post referred to an offline event in which another candidate claimed to have found an extraordinarily cheap meal, and it generated over 4,000 comments and replies. Solis mocked him, claiming to not being able to find such meal. This same candidate had also the other three most commented posts, referring to debates and public events. Not so close behind, Villalta, Araya and Guevara also accounted for several $+1,000$ comments on various posts, regarding diverse subjects like ideological stands and debates.

This goes in line with what was mentioned at the beginning regarding the capacity of each candidate to estimulate users and generate activity (positive or negative) in their profiles. Solis and Villalta were among the top commented, focusing specially on the organic and network affordances of SNS. On the other hand, Piza and, to some extent, Guevara were the least commented. This shows that, despite being the candidates who posted the most, they showed a mostly underwhelming "performance" as how much their posts resonated.

Additionally, and related to what was previously mentioned, there's an additional element that allows to expand the horizon of an investigation of this kind onto more detailed and specific approaches, that allows a clarifying view of some of the socio-political dynamics on the Internet; Table 3 is a qualitative approach of the above-stated phenomena. This table is an unstructured systematization of randomized words generated from frequency parameters. That is, an order of the most frequently used terms during the 2013-2014 presidential campaign on Facebook. Words are coded on a descendant order (top-left to bottom-right) and 
Table 3. Campaign Results, by offcial polling, Facebook activity and pre/electoral opinion poll. January 2014

\begin{tabular}{|c|c|}
\hline President & Forward \\
\hline Country & Vote \\
\hline Government & Rights \\
\hline Good & Assembly \\
\hline Fear & Life \\
\hline God & Communism \\
\hline Costa Rica & Freedom \\
\hline \multicolumn{2}{|c|}{ Labour } \\
\hline
\end{tabular}

present a variety of terms and concepts, for instance some represent the candidate's names, along with the word "President", which is a positive reinforcement, following basic communication dynamics in the candidates' strategies. Moreover, it should be noted a peculiar idiosyncratic component: the use of the word "God". This reflects the linguistic habit of Costa Rica that, in adherence to religious beliefs, uses that word in reference to wishes of good fortune and gratitude. Also, relevant terms are also shown: "Fear", "Communism", "Taxes", "Rights" and "Voting", which identify some discourse patterns that truly evidence the reflective but also parallel nature of SNS such as Facebook, being that these key topics were the most prominent all along the campaign, during televised debates and, concisely, through editorial placement in the mainstream media.

\section{Discussion}

Now, an important aspect of this research is that of taking into account what the political parties involved consider about the Internet, its value and their strategic approach towards a comprehensively interactive campaign. In this matter, results are quite disappointing; for instance, out of the five parties analyzed here, only two claimed to have an online campaign strategy(PLN and PAC). Furthermore, Araya's party was the only one to consider multiple platform usability and website reinforcement. However, as it's been previously discussed, this approach remains heavily anchored on informative aspects, relegating and neglecting the
Web 2.0 features offered by platforms such as SNS, especially Facebook. There's no indication that parties took advantage of these sites, nor that they were interested in doing it. The data-based evidence indicates that practically none of the parties gave much attention to consistently addresing Facebook as an effective medium, contrasting with what discoursively was stated. According to interview-based evidence, Facebook was always a top interest for parties and their candidates. However, as ahown to this point, the residual usage of Facebook took a toll on candidates who had a relative advantage on the virtual sphere [14], as well as on those who didn't really understood the affordances that SNS imply.

On this line, consider the case of Villalta's party a success; his organization's point of view is quiet contradictory in terms of a well-planned, strategic approach to online campaigning. PFA representatives argue that due to financial hardships their campaigning occurred mostly on the traditional side (meetings, forums, rallies, etc.) while utilizing SNS as a means of posting information easily accessible. This only changed for a brief period of time when resources were available for a more comprehensive take on all media outlets.

On the other hand, the only party that consciously develop an interactive Facebook strategy -PACpondered its possibilities differently; coinciding with the generalized financial troubles of mostly all parties, Solís' organization sought to take advantage of "free" publicity spaces, such as Facebook and Twitter profiles, the former resulting the most successful. Soon, Solís' communication team realized the affordances that Facebook offers in terms of allocating target audiences, topics (usually considered "trending") and the most proper times of day to post, getting the most out of every publication. Table 4 puts this into perspective, considering the "best" hours on which to post. Although there's no conclusive correlation between posting at a determined time of day and getting a vast response (comment, replies -all signs of image placement), it does hold up within the case of Solís (PAC), but paradoxically, not at all on Villalta's. So, the fact that practically all parties neglected the value of SNS such as Facebook as practical and/or complementary scenarios where to develop a coordinated and strategic campaign is one to worry about. This because CIEP's post

Table 4. Amount of posts made by the candidates, by time of day, October 2013 - April 2014

\begin{tabular}{|l|r|r|r|r|r|r|}
\hline Candidate/Posts & \multicolumn{1}{|l|}{$\begin{array}{l}\text { Johnny } \\
\text { Araya }\end{array}$} & $\begin{array}{l}\text { Rodolfo } \\
\text { Piza }\end{array}$ & \multicolumn{1}{l|}{$\begin{array}{l}\text { Luis G. } \\
\text { Solís }\end{array}$} & $\begin{array}{l}\text { Otto } \\
\text { Guevara }\end{array}$ & \multicolumn{1}{l|}{$\begin{array}{l}\text { José M. } \\
\text { Villalta }\end{array}$} & Total \\
\hline Before 3 p.m. & 360 & 659 & 314 & 1097 & 468 & $\mathbf{2 , 8 9 8}$ \\
\hline After 3 p.m. & 330 & 570 & 661 & & & $\mathbf{1 , 5 6 1}$ \\
\hline
\end{tabular}


electoral survey [13] showed that nearly one-third out of all voters used SNS prior and during the elections. Additionally, the same survey shows that over $70 \%$ of potential voters informed themselves via Internet and sites as Facebook or Twitter everyday and even multiple times a day. It not only evidences a withdrawal from traditional politics, but from mainstream media as well.

This suggests that with a higher incidence and Internet coverage, and SNS thusly, political processes will be further and critically assessed by the citizenship; it will distance itself from diligent politics [11] and strong party affiliation structures, diminishing the negative effects that can afflict those whom, in the absence of more open and democratic means of expression, would decide to abstain from any deliberative process and decision making (voting), likewise supporting the mobilizing thesis. That is, whether viewed as a positive or negative result, the growth of a connected population and a more mature discussion about political issues, especially campaigning, can generate greater electorate volatility, bypassing the very basis of political parties. Even though this has not been empirically proven in any part of the world, evidence shown by this Costa Rican case exemplifies that the 2014 election resulted in the most fragmented Congress in its history ( 9 parties are currently represented in the Costa Rican 57 seatsunicameral legislative house).

Now, addressing the economic side of all; as it's been said, financial constrains limited the range of possibilities for parties. Because of the funding scheme that Costa Rican laws stipulate, parties were unable to access public funds (which, by law, are the way parties ought to finance their campaigns — private donations are permitted but are heavily supervised and controlled, allowed only by donations (see Table 5)) on time for the campaign start. This would partially explain, as observed before, the cold ambience of the electoral race for the first two months. In this sense, it's growingly confusing the way that political actors neglected alternative ways to pursue some limelight, having SNS to offer quick, efficient and cheap solutions to this issue.
Such mistakes was identified and acknowledged by party representatives themselves. This also demonstrates the still traditional grip of politics and campaigning in the political reality of the country.

A key issue to support these thoughts is to assess how much money was spent by parties versus how much balloting they obtained. Although it's not a clear measure, it definitely offers some insight into the weight of traditional and non-traditional politics. Table 5 shows the differences between economic reach, and clearly displays the role of money in characterizing traditional party structures and campaigns. The interesting trait that defines this data is that two of the most succesful parties managed to do so with nearly $\$ 20,000.00$. The other high-polling party did, however, received considerable amounts of money donations and yet fell short of what one could assume should've been an easy victory. Now, this results are contradictory as PLN admittedly was the only party to mantain a continuous online strategy, albeit fousing its campaign on intensive financial spending. PFA and PAC, on the other hand, were the other parties that admitted to have had an online strategy set up for specific moments of the campaign, but focusing their main efforts on the traditional side. PML was one party that, despite being professionally counseled in terms of e-strategy, failed to achieve succesful results, both online and on the final balloting.

Finally, considering this information, it's noteworthy that neither money nor the Internet are clearly decisive and definite, however, it's been shown that parties with greater online responses had better electoral results but, what factors can explain such behaviors? It would be a risky conjecture to offer a final answer, as the electoral context developed upon several elements of distinct nature.That's to say, each party availed itself with the circumstances surrounding the party and its candidate, to exploit, or not, a valuable resource like SNS. From there, the frequency of use, interaction metrics and even money turn into indicators that fall short in explaining the end result of this particular electoral process - characterized by fragmentation, uncertainty and volatility.

Table 5. Total cash donations and valid votes for each party*.

\begin{tabular}{|l|r|r|r|r|}
\hline & \multicolumn{1}{|c|}{ January } & \multicolumn{1}{c|}{ February } & \multicolumn{1}{c|}{ Total** } & \multicolumn{1}{c|}{ Polling*** } \\
\hline PLN & $337.528 .625,00$ & $119.547 .550,00$ & $457.076 .175,00$ & $28,98 \%$ \\
\hline PFA & $8.622 .500,00$ & $1.203 .000,00$ & $9.825 .500,00$ & $15,90 \%$ \\
\hline PAC & $11.923 .400,60$ & - & $11.923 .400,60$ & $28,31 \%$ \\
\hline PUSC & $350.000,00$ & $20.000,00$ & $370.000,00$ & $8,38 \%$ \\
\hline ML & $120.702 .700,00$ & $13.256 .000,00$ & $133.958 .700,00$ & $10,08 \%$ \\
\hline
\end{tabular}

*Donations accounted for January-February (2014) period.

**Figures are presented in Costa Rican Colon (CRC). Exchange \$1= CRC540

${ }^{* * *}$ Valid votes at the February 2 nd election. 


\section{Final Considerations}

Now, having reviewed the most important aspects of what the 2014 presidential race in Costa Rica meant in terms of lessons and basis for a more solid Information Society, the main element of this paper must be addressed; Figure 6 indicates the way the electorate behaved in different instances of "polling"; first, the vote on February 2nd, 2014, then by measuring the activity registered in Facebook (as a percentage of the total activity), and finally contrasting these to the results published by CIEP in its surveys (averaging the last two pre-election polls ). All data accounts for January. As shown, both the opinion poll, as the data used Facebook blundered the order of the top three candidates, however, it was the virtual tool that was closer to the end result, as for it "predicted" Solís' victory. However, both this measurement, such as the one by CIEP, was wrong about Villalta. Likewise, it is noteworthy the precision observed in the cases of Piza and Guevara because, despite their irregular use of Facebook, January's activity shows a surprisingly close turnout to that obtained in the official polling. It is also clear, due to the nature and the affordances of SNS, and according to the parameters observed, there will be inflated results in relation to projections and other outcomes.

This leads to think in political parties, which are the institutional apparatus by means of which the candidates aspire to the popularly elected positions. In other words, these are the instances that need to more closely observe the virtualization of politics since, as shown here, they have been unable to assimilate -structurally- the new dynamics involved. New strategies should be refined in order to generate not only content, but interaction spaces that allow people to approach them from a truly 2.0 perspective. People have already started their own, virtually endogenous, processes of interaction; parties must update to this trend or if not, at the expense of themselves, downgrade and lose electoral support; or, put differently, if politicians do not adopt Internet politics, it will be the citizens who use it against them [15].

Considering the initial question stated at the beginning; does the Internet, specifically social networking, work predictably with respect to the political behavior of people in the offline world? Or, on the contrary, are SNS simple reflections of the conduct of the real world? That is, does the Internet normalize or mobilize the political-electoral dynamics? As it's been shown, its predictive capability exists, and therefore represents an exceptional tool that academics and politicians should take advantage of. In addition, due

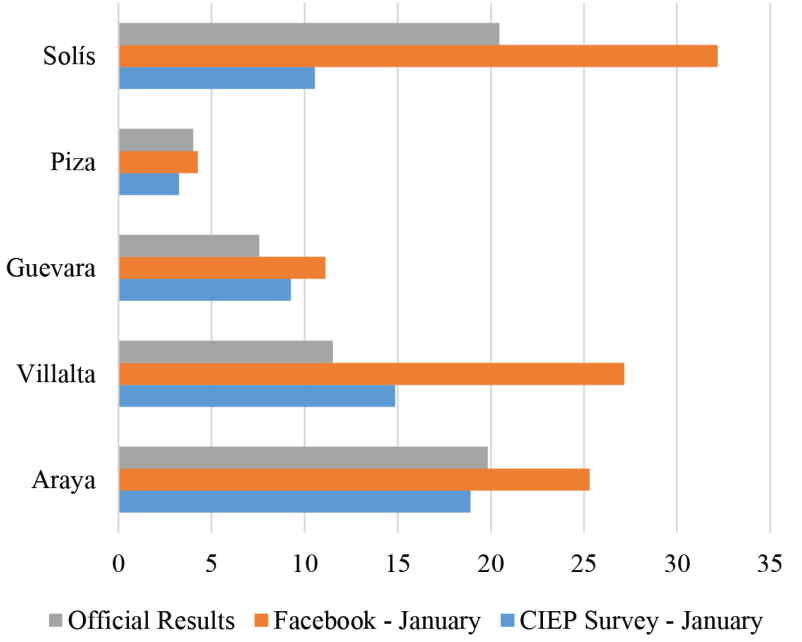

Figure 6. Campaign Results, by offcial polling, Facebook activity and pre/electoral opinion poll. January 2014

to the analyzed characteristics of virtual campaigning carried out by candidates and their parties, must be considered not only a valid option, but an obligatory and successful one. Internet, via Considering the initial question stated at the beginning; does the Internet, specifically social networking, work predictably with respect to the political behavior of people in the offline world? Or, on the contrary, are SNS simple reflections of the conduct of the real world? That is, does the Internet normalize or mobilize the political-electoral dynamics? As it's been shown, its predictive capability exists, and therefore represents an exceptional tool that academics and politicians should take advantage of. In addition, due to the analyzed characteristics of virtual campaigning carried out by candidates and their parties, must be considered not only a valid option, but an obligatory and successful one. Internet, via SNS, normalizes through mobilizing previously displeased and disinterested voters and other population segments. As Bimber, Cantijoch, Copeland and Gibson [16] affirm, SNS reinforce traditional means of political participation, voting emphatically.

\section{Acknowledgements}

This paper was based on the research conducted at the University of Costa Rica, in a collaborative effort by PROSIC and CITIC. Special thanks to anyone who participated in the research design, data extraction, processing and editing. Thanks to colleagues who constantly reviewed it and contributed with critique and ideas. 


\section{Footnotes}

1. This was determined by survey popularity [1]. In that manner, these parties are as follows:

- Partido Liberación Nacional (PLN) for Johnny Araya,

- Partido Frente Amplio (PFA) for José M. Villalta,

- Partido Movimiento Libertario (PML) for Otto Guevara,

- Partido Acción Ciudadana (PAC) for Luis G. Solís and Partido Unidad Socialcristiana (PUSC) for Rodolfo Piza.

\section{References}

[1] Cruz, R. (2015). "Politics 2.0: The use of ICTs in the Costa Rican 2014 presidential campaign", in Proceedings of the 2015 i-Society International Conference, Infonomics Society: London, UK. p.115

[2] Red 506 (2015). Estudio que detalla el uso que hacen los costarricenses de Internet y redes sociales [Study on how are Costa Ricans using Internet and social networks].El Financiero. http://www.elfinancierocr.com/ gnfactory/especiales/2015/red506/ResumenRED506.pdf (15 september 2015).

[3] Martin, J. A. (2014). 'Mobile media and political participation: Defining and developing an emerging field'. Mobile Media \& Communication, 2(2), 173-195.

[4] Tewksbury, D. \& Rittenberg, J. (2009). 'Online news creation and consumption. Implications for modern democracies' in Chadwick, A. \& Howard. P.H. (Eds.) Routlegde handcook of Internet politics. London: Routlegde.

[5] CIEP, "Electoral opinion poll". University of Costa Rica: San José. January, 2014. [6] B. Enjolras, K. Steen-Johnsen, and D. Wollebaek, "Social media and mobilization to offline demonstrations: Transcending participatory divides?," New Media \& Society, vol. 15, no. 6, pp. 890-908, Sep. 2013.

[7] F. Hirzalla, L. van Zoonen, and J. de Ridder, "Internet Use and Political Participation: Reflections on the Mobilization/Normalization Controversy," The Information Society, vol. 27, no. 1, pp. 1-15, Dec. 2011.

[8] D. G. Lilleker, K. Koc-Michalska, E. J. Schweitzer, M. Jacunski, N. Jackson, and T. Vedel, "Informing, engaging, mobilizing or interacting: Searching for a European model of web campaigning," European Journal of Communication, vol. 26, no. 3, pp. 195-213, 2011.

[9] M. Xenos and W. Lance Bennett, "The Disconnection In Online Politics: the youth political web sphere and US election sites, 2002-2004," Information, Communication \& Society, vol. 10, no. 4, pp. 443-464, Aug. 2007.
[10] G. Elmer, "Live research: Twittering an election debate," New Media Society, vol. 15, no. 1, pp. 18-30, Feb. 2013.

[11] C. Wells, "Two eras of civic information and the evolving relationship between civil society organizations and young citizens," New Media Society, vol. 16, no. 4, pp. 615-636, Jun. 2014.

[12] E. Anduiza and C. Galais, "The contextual conditionings of digital media effects on civic attitudes" in Europpean Consortium for Political Research. 2011. Retrieved from: http://new.ecpr.eu/Filestore/PaperProposal/ 99d454d8-173e-40ea-b03c-5b6e7a36bb44.pdf.

[13] CIEP, "Post-electoral opinion poll". University of Costa Rica: San José. February, 2014.

[14] Papacharissi, Z. (2002). The virtual sphere. The internet as a public sphere. New Media \& Society, 4(1), 927.

[15] M. Castells, "Democracy in the age of the Internet" in Journal of Contemporary Culture, No. 6, pp. 96-103, 2011.

[16] B. Bimber, M. C. Cunill, L. Copeland, and R. Gibson, "Digital Media and Political Participation The Moderating Role of Political Interest Across Acts and Over Time," Social Science Computer Review, vol. 33, no. 1, pp. 21-42, Feb. 2015

[17] Vráblíková, K. (2014). "How Context Matters? Mobilization, Political Opportunity Structures, and Nonelectoral Political Participation in Old and New Democracies". Comparative Political Studies, 47(2), 203229. 